\title{
Theoretical, Spectroscopic and Crystal Structure Investigation of a Novel Selenomolybdate $\left(\mathrm{NH}_{4}\right)_{4}\left[\mathrm{Se}_{2} \mathrm{MO}_{5} \mathrm{O}_{21}\right] \cdot 3 \mathrm{H}_{2} \mathrm{O}$
}

\author{
Jihen Ajmi, ${ }^{1,2, *}$ Ichraf Nagazi, ${ }^{1,2}$ Takoua Ben Issa, ${ }^{3}$ Ali Harchani, ${ }^{1,2}$ Amor Haddad ${ }^{1,2}$
}

\author{
1 Laboratory of Materials, Cristallochemistry and Applied Thermodynamics University El Manar, Tunisia \\ 2 Faculty of Sciences of Monastir, University of Monastir, Tunisia \\ 3 Laboratory of Interfaces and Advanced Materials, Faculty of Sciences of Monastir, University of Monastir, Tunisia \\ * Corresponding author's e-mail address: jihenajmi33@gmail.com
}

RECEIVED: December 9, 2019 * REVISED: May 27, 2020 * ACCEPTED: May 27, 2020

\begin{abstract}
The current investigation undertakes the synthesis, crystal structure, spectroscopic, thermal analyses and theoretical calculations of a new $3 \mathrm{D}$ Strandberg-type polyoxometalate-based inorganic $\left(\mathrm{NH}_{4}\right)_{4}\left[\mathrm{Se}_{2} \mathrm{MO}_{5} \mathrm{O}_{21}\right] \cdot 3 \mathrm{H}_{2} \mathrm{O}$ (denoted as ASH). Structural data obtained by single crystal X-ray diffraction revealed that the titled compound crystallizes in orthorhombic system with $P b c n$ space group, having parameters $a=$ 15.0927(2) $\AA, b=13.3633(1) \AA, c=23.8204(3) \AA$ and $Z=8$. Molecular structure and spectroscopic analysis were performed using experimental techniques like X-ray diffraction, infrared spectrum, UV-visible spectroscopy and thermogravimetric analysis. Hirshfeld surface analysis was performed to study the intermolecular interactions. The structural arrangement is mainly made by a system of $\mathrm{H}$-bonds. All Strandberg clusters anions $\left[\mathrm{Se}_{2} \mathrm{Mo}_{5} \mathrm{O}_{21}\right]^{4-}$ are connected to each other through water molecules and the ammonium groups $\mathrm{NH}_{4}{ }^{+}$to build a $3 \mathrm{D}$ (3 dimensional) supramolecular framework. Theoretical calculations were performed using PM3 semi-empirical model and several properties were studied.
\end{abstract}

Keywords: Strandberg clusters, crystal structure, electrochemical properties and theoretical study.

\section{INTRODUCTION}

S INCE its first discovery in 1727 ,[1] $^{1]}$ polyoxometalates (POMs) has attracted more and more attention of scientists all over the world. ${ }^{[2]}$ The attraction to POMs is most likely due to their superior properties such as controlled functionalities and chemical tenability. POMs figure prominently in myriad applications, especially medicinal, ${ }^{[3]}$ photochemical uses, ${ }^{[4]}$ drug, protein delivery, ${ }^{[5]}$ and chemical separation. ${ }^{[6]}$ From a structural point of view, the first structural identification of these fascinating materials was in 1862 by Marignac et al. ${ }^{[7]}$ Sixty years later, the isolation of single crystals from molybdenum blue solutions revealed the huge polyoxometalate wheel structure encapsulating 158 Molybdenum atoms. This discovery was considered as a real start announcing the opening of new fields in nano-materials and nanochemistry in general.

In the fields of POMs, Strandberg heteropolyanion is a considerable class of polyoxometalate family grouped under this general formula $\left[\mathrm{X}_{2} \mathrm{Mo}_{5} \mathrm{O}_{21}\right]^{n-}$. It can be showed as two $\mathrm{XO}_{y}$ polyhedral $(y=3$ if $\mathrm{X}=\mathrm{Se}, y=4$ if $\mathrm{X}=\mathrm{P}$ ). These structures are dissymmetric and hence expected to be chiral. ${ }^{[8]}$ Consequently, Strandberg hetero-polyanion family is a prominent building block which remain a fruitful area of interest due to its higher charge density regarding its relatively smaller size in comparison with other POMs Recent investigations prove that different molecular structure with various arrangement (1, 2, 3 dimensional) have further encouraged researchers to create new architectures based on this kind of polyoxoanions. Thus, we report, here, the preparation and growth of the new polyoxometalate $\left(\mathrm{NH}_{4}\right)_{4}\left[\mathrm{Se}_{2} \mathrm{Mo}_{5} \mathrm{O}_{21}\right] \cdot 3 \mathrm{H}_{2} \mathrm{O}$. The aim of this study is to improve our knowledge about its crystal structure and probed its spectroscopic properties in order to investigate the correlation between them. The present work reports, the syntheses and structural characterization by single-crystal X-ray diffraction, spectroscopy, UV-visible spectroscopy and the TG-DTA (thermal behavior). Furthermore, the electrochemical properties and non-bonding

(c) Br This work is licensed under a Creative Commons Attribution 4.0 International License. 
interactions of these compounds have been studied with the help of the Hirshfeld surfaces. The HOMO-LUMO energy gap were calculated. After that, some descriptions about thermochemical properties were added.

\section{EXPERIMENTAL}

\section{General Procedure for Chemical preparation of $\left(\mathrm{NH}_{4}\right)_{4}\left[\mathrm{Se}_{2} \mathrm{Mo}_{5} \mathrm{O}_{21}\right] \cdot 3 \mathrm{H}_{2} \mathrm{O}(\mathrm{ASH})$}

A mixture of Ammonium heptamolybdate tetrahydrate $\left(\mathrm{NH}_{4}\right)_{6} \mathrm{Mo}_{7} \mathrm{O}_{24} \cdot 4 \mathrm{H}_{2} \mathrm{O}(2 \mathrm{mmol})$ and $\mathrm{H}_{2} \mathrm{SeO}_{3}(2 \mathrm{mmol})$ was dissolved in $30 \mathrm{~mL}$ of water. Then, $0.5 \mathrm{mmol}$ of $N, N^{\prime}$-dicyclohexylcarbodiimide $\left(\mathrm{C}_{13} \mathrm{H}_{22} \mathrm{~N}_{2}\right)$ was added to the solution. The obtained preparation was stirred and heated to $150{ }^{\circ} \mathrm{C}$ for one hour. The $\mathrm{pH}$ of the solution was adjusted to 3 using hydrochloric acid $\mathrm{HCl}(3 \mathrm{M})$.

The final solution was left at room temperature to evaporate. Four days later, color-less crystals suitable for $\mathrm{X}$-ray diffraction were obtained and were harvested from the solution.

\section{X-ray Diffraction Analysis}

SuperNova, dual diffractometer with Mo Ka monochromatic radiation $(\lambda=0.71073 \AA)$ was performed to collect X-ray intensity data. The structure was solved by Patterson method using SHELXS2013/7[9] program, which allows localizing the molybdenum atoms. The remaining nonhydrogen atoms were found by the successive difference Fourier maps using the SHELXL-2014..$^{[9]}$ The hydrogen atoms attached to oxygen were geometrically located and refined with isotropic thermal parameters. A summary of the crystallographic data and structure refinements of ASH is given in Table 1.

Thermal ellipsoid plots are obtained using ORTEP3 program. ${ }^{[10]}$ All the molecular graphics are made with Diamond 2.1. ${ }^{[11]}$

The intermolecular interactions within the investigated complex were quantified using HS analysis and fingerprint plots using the Crystal Explorer 3.1 software ${ }^{[12]}$ and TONTO ${ }^{[13]}$ system.

\section{Materials and Measurements}

All the products were purchased commercially and used without additional purification. At room temperature, FT-IR spectrum was recorded using Perkin Elmer UATR in the range between $4000-400 \mathrm{~cm}^{-1}$. UV-Vis spectrum was recorded using Perkin-Elmer Lambda 19 spectrophotometer in the spectral domain between 180 and $800 \mathrm{~nm}$. In nitrogen atmosphere, SETARAM TG-DTA 92-12 was used to perform the thermal analysis at a heating rate of $10^{\circ} \mathrm{C} / \mathrm{min}$. Electrochemical measurements were performed using a traditional three-electrode cell, which contain a platinum
Table 1. Cristallographic data of compound (ASH)

\begin{tabular}{|c|c|}
\hline \multicolumn{2}{|l|}{ Crystal data } \\
\hline Empirical formula & $\left(\mathrm{NH}_{4}\right)_{4}\left[\mathrm{Se}_{2} \mathrm{Mo}_{5} \mathrm{O}_{21}\right] \cdot 3 \mathrm{H}_{2} \mathrm{O}$ \\
\hline $\mathrm{M} / \mathrm{g} \mathrm{mol}^{-1}$ & 1099.84 \\
\hline Crystal system & Orthorhombic \\
\hline Space group & $P b c n$ \\
\hline Z & 4 \\
\hline \multicolumn{2}{|l|}{ Lattice parameters } \\
\hline$a / \AA$ & $15.0927(2)$ \\
\hline$b / \AA$ & $13.3633(1)$ \\
\hline$c / \AA$ & $23.8204(3)$ \\
\hline$V / \AA^{3}$ & $4804.56(2)$ \\
\hline$D_{\text {calc }} / \mathrm{g} \mathrm{cm}^{-3}$ & 0.760 \\
\hline Absorption coefficient, $\mu / \mathrm{mm}^{-1}$ & 1.42 \\
\hline$F_{000}$ & 1040 \\
\hline Crystal size / mm & $0.22 \times 0.14 \times 0.10$ \\
\hline \multicolumn{2}{|l|}{ Intensity measurement } \\
\hline$\lambda(\mathrm{Mo} \mathrm{K \alpha}) / \AA$ & $\lambda=0.71073$ \\
\hline$T / K$ & 293 \\
\hline Numbe of measured reflexions & 67516 \\
\hline Number of independent reflexions & 5257 \\
\hline \multicolumn{2}{|l|}{ Structure determination } \\
\hline Unique reflexion included $(I>2 \sigma(I))$ & 4903 \\
\hline Number of refined parametrs & 348 \\
\hline Absorption correction & $\psi$-scan \\
\hline$T_{\min }, T_{\max }$ & $0.384,0.743$ \\
\hline$R\left[F^{2}>2 \sigma\left(F^{2}\right)\right], w R\left(F^{2}\right)$ & $0.023,0.061$ \\
\hline \multicolumn{2}{|l|}{ Extinction coefficient } \\
\hline Goodness of fit on $F^{2}, S$ & 1.09 \\
\hline$\left(\Delta \rho_{\min } / \Delta \rho_{\max }\right) /\left(\mathrm{e} \AA^{-3}\right)$ & $-1.25 / 1.51$ \\
\hline
\end{tabular}

wire as a counter electrode and glassy carbon electrode (GCE) as working electrode with a geometric area of 0.07 $\mathrm{cm}^{2}$. In saturated $\mathrm{KCl}(\mathrm{Ag}|\mathrm{AgCl}|($ sat. $\mathrm{KCl}))$, the $\mathrm{Ag} \mid \mathrm{AgCl}$ was the reference electrode. For this analysis, $2 \mathrm{mg}$ of the product (ASH) was dispersed in $1 \mathrm{~mL}$ of solvent: water. Then, $5 \mathrm{~mL}$ of the obtained solution was dropped directly on the surface of a clean glassy carbon electrode GCE surface and dried at room temperature to form a ASH modified GCE. The electrochemical measurements were carried out using an Auto lab PGSTAT $320 \mathrm{~N}$ potentiostat for impedance spectroscopy spectra measurements controlled by computer with software (NOVA 1.5) for data analysis.

\section{DFT Calculation Details}

The semi-empirical calculations of ASH were performed by the Spartan 14 V1.1.4 Wave function molecular modeling 
suite package on a personal computer ${ }^{[14]}$ using $\mathrm{PM} 3$ semiempirical model. The PM3 semi empirical models were parameterized for most transition metals, and they usually provide good results. ${ }^{[15]}$ The DFT structure optimization of ASH was executed, starting from the X-ray geometry. The method, which is developed by Hohenberg and Kohn has been proved to be a good tool for the theoretical rationalization of structural properties. ${ }^{[16,17]}$ Therefore, in this study, Becke's three-parameter functional with the Lee-Yang-Parr (B3LYP) correlation functional ${ }^{[18,19]}$ and the $6-311++G(2 d, 2 p)$ basis set implemented in the Gaussian 09 program. The Gauss View program was used for visualization of the structure and simulation of the vibrational spectra.

\section{RESULT AND DISCUSSION}

\section{Description of the Crystal Structure}

Single crystals of the investigated complex belong to the centro symmetric Pbcn space group of the orthorhombic system with eight formula units $(Z=8)$. The asymmetric unit reported in Figure 1 shows that the ASH contains four ammonium cations, three water molecules and one anionic cluster of $\left[\mathrm{Se}_{2} \mathrm{Mo}_{5} \mathrm{O}_{21}\right]^{4-}$.

The structure of the compound can be described as Strandberg polyoxomolybdates $\left[\mathrm{Se}_{2} \mathrm{Mo}_{5} \mathrm{O}_{21}\right]^{4-}$ assembled in a 1D zigzag chain through the coordination of the terminal oxygen atoms with water molecule. Then each chain is connected to two other parallel chains through ammonium cations forming a 2D layer. Adjacent layers are further joined together to yield a 3D supramolecular architecture through a complex network of $\mathrm{N}-\mathrm{H} \cdots \mathrm{O}, \mathrm{OW}-$ $\mathrm{H} \cdots \mathrm{O}$ and $\mathrm{OW}-\mathrm{H} \cdots \mathrm{O}$ hydrogen bonding and Van der Waals

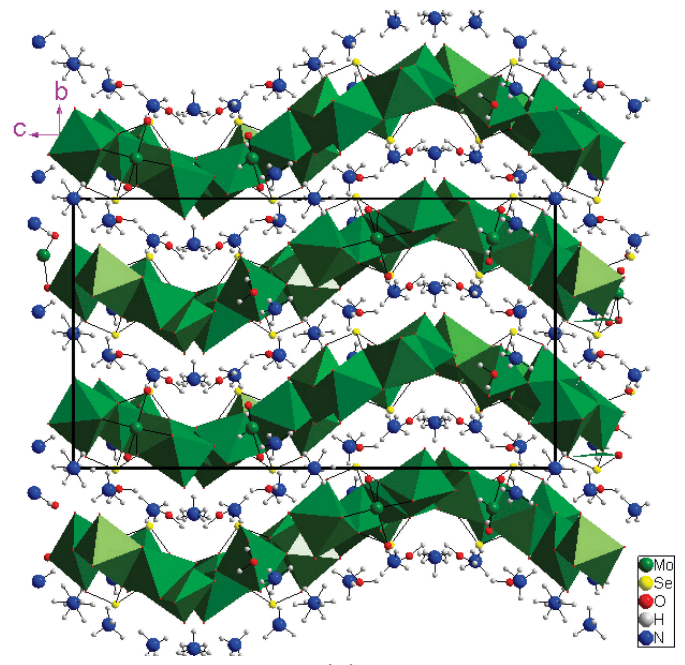

(a)

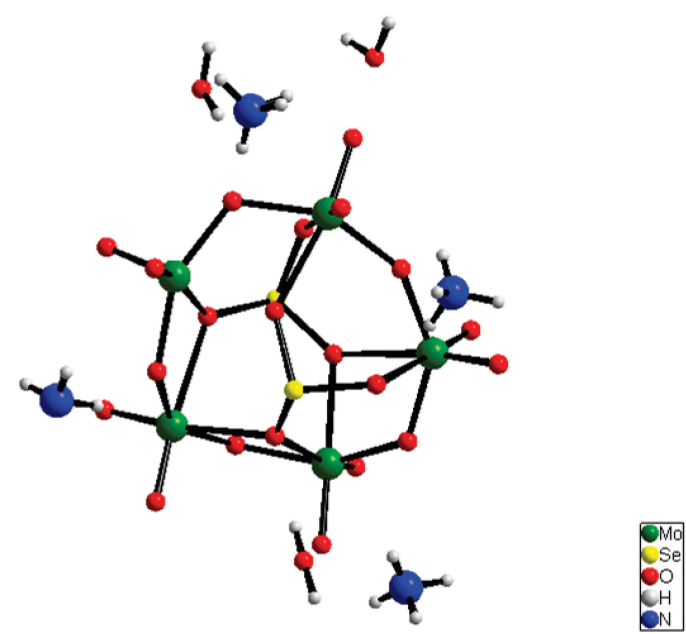

Figure 1. Unit cell structure of the new compound $\left(\mathrm{NH}_{4}\right)_{4}\left[\mathrm{Se}_{2} \mathrm{Mo}_{5} \mathrm{O}_{21}\right] \cdot 3 \mathrm{H}_{2} \mathrm{O}$.

interactions (Figure 2a and Figure 2b).

The mineral skeleton is mainly formed by $\left[\mathrm{Se}_{2} \mathrm{Mo}_{5} \mathrm{O}_{21}\right]^{4-}$ cluster which consists of five contortive $\left[\mathrm{MoO}_{6}\right]$ octahedra and two $\left(\mathrm{SeO}_{3}\right)$ trigonal pyramids. The five $\left[\mathrm{MoO}_{6}\right]$ octahedra form a ring through corner-sharing and edge-sharing. The two $\left(\mathrm{SeO}_{3}\right)$ pyramids are further linked to each side of the ring by sharing three oxygen atoms of different units of $\left[\mathrm{MoO}_{6}\right]$ by an assembly of five distorted edge and corner-sharing octahedra to form a $\left[\mathrm{Mo}_{5} \mathrm{O}_{21}\right]^{6-}$ cluster. As shown in Figure 3, the $\left[\mathrm{Se}_{2} \mathrm{Mo}_{5} \mathrm{O}_{21}\right]^{4-}$ anionic cluster has an approximated $\mathrm{C}_{2}$ symmetry. The axis passes through the unique corner-sharing oxygen atom $\left(\mathrm{O}_{7}\right)$ and the opposite molybdenum $\left(\mathrm{Mo}_{5}\right)$. Three different types of oxygen depending on their chemical environment and ten terminal oxygen atoms denoted $\mathrm{O}_{t}$ are connected

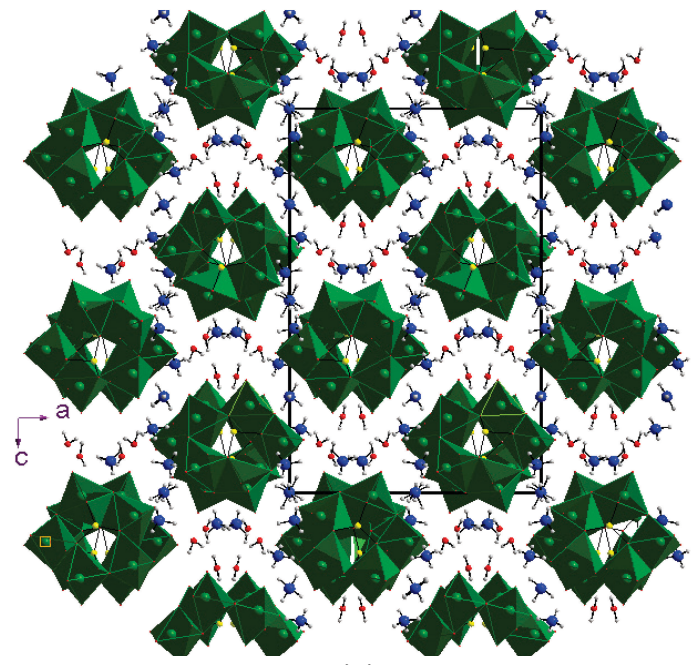

(b)

Figure 2. Projection of the structure along the crystallographic a and b axis respectively. 
Table 2. Selected bond lengths ( $\AA$ ) for compound (ASH)

\begin{tabular}{cccccc}
\hline Selected bond & X-ray & DFT & Selected bond & X-ray & DFT \\
\hline Mo1-016 & $1.701(3)$ & 1.7525 & Mo4-017 & $1.703(3)$ & 1.7540 \\
Mo1-021 & $1.714(3)$ & 1.7549 & Mo4-09 & $1.712(3)$ & 1.7516 \\
Mo1-05 & $1.921(3)$ & 1.9546 & Mo4-020 & $1.911(3)$ & 1.9632 \\
Mo1-06 & $1.927(3)$ & 1.9823 & Mo4-019 & $1.952(3)$ & 1.9373 \\
Mo1-015 & $2.312(3)$ & 2.2058 & Mo4-011 & $2.290(3)$ & 2.2971 \\
Mo1-010 & $2.379(3)$ & 2.3819 & Mo4-014 & $2.292(3)$ & 2.3889 \\
Mo2-012 & $1.700(3)$ & 1.7518 & Mo5-01 & $1.707(3)$ & 1.7516 \\
Mo2-02 & $1.730(3)$ & 1.7518 & Mo5-04 & $1.717(3)$ & 1.7539 \\
Mo2-07 & $1.891(3)$ & 1.9357 & Mo5-019 & $1.935(3)$ & 1.9373 \\
Mo2-020 & $1.908(3)$ & 1.9358 & Mo5-06 & $1.955(3)$ & 1.9630 \\
Mo2-08 & $2.326(3)$ & 2.4058 & Mo5-011 & $2.162(3)$ & 2.2978 \\
Mo2-013 & $2.329(3)$ & 2.4056 & Mo5-010 & $2.343(3)$ & 2.3849 \\
Mo3-03 & $1.703(3)$ & 1.7549 & & & \\
Mo3-018 & $1.716(3)$ & 1.7525 & & & \\
Mo3-07 & $1.928(3)$ & 1.9544 & & & \\
Mo3-05 & $1.946(3)$ & 1.9824 & & & \\
Mo3-013 & $2.224(3)$ & 2.2058 & & & \\
Mo3-015 & $2.303(3)$ & 2.3822 & & & \\
\hline
\end{tabular}

to Mo atoms. Five oxygen atoms located between two successive Mo atoms are named as $\mathrm{O}_{\mathrm{b}}$. Moreover, each selenite atom shares three oxygen groups with the molybdate. It is important to mention that, two of these oxygen's adopts the $\mu_{2}$-bridging mode linked to one molybdenum and one selenium atoms whereas the remained oxygen atoms adopt the $\mu_{3}$-bridging mode. The detailed geometry of all the entities illustrated in Table 2 . It is worthy to note that $\mathrm{Se}-\mathrm{O}$ and Mo-O bond lenghts are found to be in the range between $(1.700(3)-2.343(3) \AA$ ) and $(1.667(3)-1.724(3) \AA)$, respectively. These are typical values observed for other POMs recently investigated. [20-22] Bond valence sum calculations indicate that all the molybdenum atoms, selenium atoms are hexavalent and tetravalent respectively and all oxygen atoms have values close to 2 .

As represented in Figure 2, anionic clusters $\left[\mathrm{Se}_{2} \mathrm{Mo}_{5} \mathrm{O}_{21}\right]^{4-}$ are isolated from each other and arranged in a zigzag form along $a$ axis. Each anionic cluster is coordinated by four water molecules to form an anionic layer $\left\{\left(\mathrm{H}_{2} \mathrm{O}\right)_{4}\left[\mathrm{Se}_{2} \mathrm{Mo}_{5} \mathrm{O}_{21}\right]\right\}^{4-}$ that extends along $(a, b)$ plane. These alternative layers are isolated from each other but the only connection is mainly ensured via the ammonium part. As illustrated in Figure 2 ( $a$ and $b$ ), ammonium groups are incorporated in the grooves between the neighboring 2D layers. These groups are also arranged to form zigzag

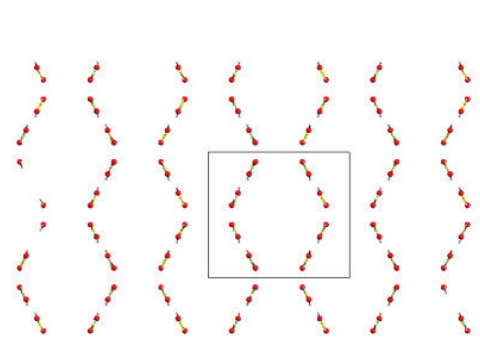

(a)

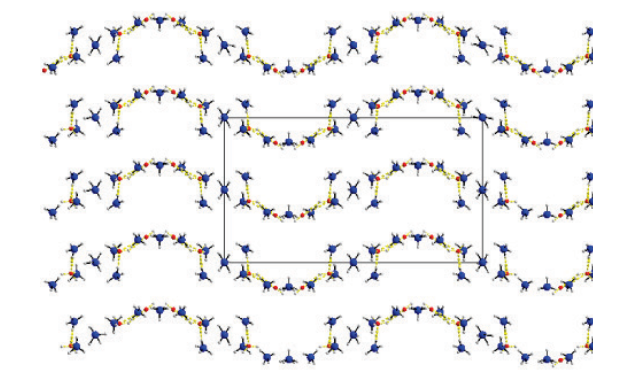

(b)

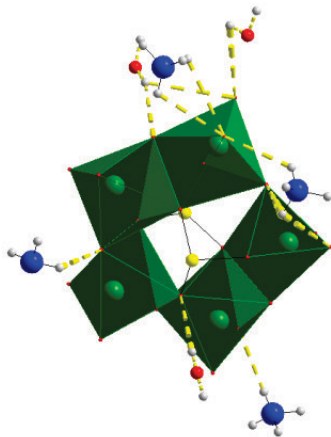

(c)

Figure 3. Arrangement of water molecules in the structure (a); hydrogen bond between the water molecules and ammonium cations (b); hydrogen bonding $\mathrm{N}-\mathrm{H} \cdots \mathrm{O}$, and $\mathrm{OW} \cdots \mathrm{H}-\mathrm{O}$ interactions within the cluster anions $\left[\mathrm{Se}_{2} \mathrm{Mo}_{5} \mathrm{O}_{21}\right]^{4-}$ (c). 
Table 3. Selected bond lengths $(\AA ̊ \AA)$ for $\mathrm{NH}_{4}{ }^{+}$cation

\begin{tabular}{cccc}
\hline Selected bond & X-ray & Selected bond & X-ray \\
N1-H1N & $0.893(4)$ & N3-H11N & $0.770(4)$ \\
N1-H2N & $0.951(4)$ & N3-H12N & $0.858(19)$ \\
N1-H3N & $1.000(4)$ & N4A-H41A & 1.0765 \\
N1-H4N & $0.906(4)$ & N4A-H42A & 1.0471 \\
N2-H5N & $0.927(5)$ & N4A-H44A & $0.87(2)$ \\
N2-H6N & $0.910(5)$ & N4A-H43A & $0.85(2)$ \\
N2-H7N & $0.929(6)$ & N4B-H41B & $0.88(2)$ \\
N2-H8N & $0.893(5)$ & N4B-H42B & $0.88(2)$ \\
N3-H9N & $0.996(4)$ & N4B-H43B & $0.87(2)$ \\
N3-H10N & $0.877(14)$ & N4B-H44B & $0.86(2)$ \\
\hline
\end{tabular}

layers along $a$ axis. Their projection along $c$ axis shows that ammonium groups are arranged in two different layers (Figure 2.b). Furthermore, $\left(\mathrm{NH}_{4}\right)^{+}$ligands acting as bidentate linkers connect water molecule and anionic clusters $\left[\mathrm{Se}_{2} \mathrm{Mo}_{5} \mathrm{O}_{21}\right]^{4-}$.

In addition, water molecule plays a crucial role in the crystal assembly of the investigated complex. A projection along $a$ and $c$ axis shows that these entities are arranged to form zigzag layers and create hexagonal grooves in which POMs were located. At the same level, $\mathrm{H}$-bonding plays a significant role in linking ammonium groups with anionic clusters $\left\{\left(\mathrm{H}_{2} \mathrm{O}\right)_{4}\left[\mathrm{Se}_{2} \mathrm{Mo}_{5} \mathrm{O}_{21}\right]\right\}^{4-}$ and assure the stability along with the cohesion of the crystal packing. The extensive hydrogen bonging in the crystal structure of the titled compound is listed in Table 3, with an upper limit of $2.776 \AA$ for $\mathrm{H} \cdots \mathrm{A}$ distance and a lower limit of $143^{\circ}$ for the $\mathrm{D}-\mathrm{H} \cdots \mathrm{A}$ bond angles. The presence of the specific $\mathrm{H}$-bonds between two neighboring water molecules was also noticed. These $\mathrm{H}$-bonds are commonly called Tandem H-bond. ${ }^{[23]}$ The strongest $\mathrm{H}$-bonds are $\mathrm{OW}_{2}-\mathrm{H}_{4} \cdots \mathrm{O} 19, \mathrm{~N}_{1}-\mathrm{H}_{2} \mathrm{~N} \cdots \mathrm{OW}_{2}$, $\mathrm{N}_{3}-\mathrm{H}_{9} \mathrm{~N} \cdots \mathrm{O}_{6}, \mathrm{~N}_{4 A}-\mathrm{H}_{41 \mathrm{~A}} \cdots \mathrm{O}_{1}, \mathrm{~N}_{4 A}-\mathrm{H}_{42 \mathrm{~A}} \cdots \mathrm{O}_{2}$, and $\mathrm{N}_{1}-\mathrm{H}_{3} \mathrm{~N} \cdots \mathrm{O}_{8}$. These hydrogen bonds hold the components together into a three dimensional network and make the crystal structure of the compound more stable.

\section{Optimized Structure}

The theoretical calculation using the Gaussian 09 program package make use of the B3LYP (three parameter BeckeLee-Yang-Parr) method with the $6-311++G(2 d, 2 p)$ basis set is employed to optimized the bond lengths and angles. Concerning the inter-atomic parameters in the $\left[\mathrm{Se}_{2} \mathrm{Mo}_{5} \mathrm{O}_{21}\right]^{4-}$, it can be noticed that the difference between experimental and theoretical values of $\mathrm{Mo}-\mathrm{O}$ and Se-O distances do not surpass $0.159 \AA$ and $0.068 \AA$ respectively. Additionally, the mean absolute deviations of the calculated O-Mo-O with experimental ones are in the ranges of $1.55^{\circ}-6.47^{\circ}$ respectively. The comparison of the experimental data with those obtained by the theoretical study reveals that all optimized bond lengths and bond angles are slightly larger than the experimental values (Table 2). The difference between the experimental and calculated value may origin from the fact that the experimental data was obtained in the solid state, as the calculated values refer to isolated molecules without considering lattice interactions. Overall, the observed and calculated parameters are in good agreement.

Hirshfeld surface analysis

Hirshfeld surface (HS) analysis is a powerful technique used to understand the nature of intermolecular interactions which allows easy identification of characteristic interactions within a crystal structure using 3D HSs and 2D fingerprint plots (FPs). ${ }^{[24]}$ Recently, this method has received considerable attention as a graphical analyzer of intermolecular interactions and has been applied to study such interactions in diverse molecular and ionic compounds. [25]

The HS reflects the proximity of neighboring atoms and molecules, and hence intermolecular interactions, in a visual manner which offers a 3D picture of molecular shape in a crystalline environment. ${ }^{[26]}$ For each point on the HS, a pair distance ( $d_{-} \mathrm{e}, d_{-} \mathrm{i}$ ) is defined, the distances from the point to the nearest nucleus external (d_e) and internal $\left(d \_i\right)$ to the surface. A $d_{-}$norm surface plotted by using the program Crystal Explorer $17^{[27]}$ that allows for easy comparison of intermolecular contacts relative to Van der Waals radii by way of a simple red-white-blue color scheme. In fact, red spots exhibit short contacts (with distances shorter than the sum of van der Waals radii), while white areas represent contacts with distances equal to the sum of the van der Waals radii, and blue regions are free of any close contacts. ${ }^{[28]}$

The d_norm, $d$ _e and d_i surfaces of ASH is shown in Figure 4. For this polyoxometalates compound, the fixed scale color of 3D $d \_$norm mapped surfaces is between 
Table 4. Hydrogen bonds of compound (ASH)

\begin{tabular}{|c|c|c|c|c|c|}
\hline $\mathrm{D}-\mathrm{H} \cdots \mathrm{A}$ & $\mathrm{D}-\mathrm{H}$ & $\mathrm{H} \cdots \mathrm{A}$ & D-HA & $D \cdots A$ & Symmetry code \\
\hline $\mathrm{OW} 1-\mathrm{H} 1 \cdots \mathrm{O} 16$ & 0.882 & 2.163 & 134.09 & 2.848 & $x-1 / 2,-y+1 / 2,-z+1$ \\
\hline $\mathrm{OW} 1-\mathrm{H} 1 \cdots \mathrm{O} 21$ & 0.882 & 2.596 & 132.97 & 3.261 & \\
\hline 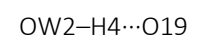 & 0.832 & 1.998 & 156.32 & 2.78 & $-x,-y,-z+1$ \\
\hline $\mathrm{OW} 2-\mathrm{H} 3 \cdots \mathrm{OW} 3$ & 0.848 & 2.117 & 148.38 & 2.874 & $x-1 / 2,-y+1 / 2,-z+1$ \\
\hline $\mathrm{N} 2-\mathrm{H} 5 \mathrm{~N} \cdots \mathrm{O}$ & 0.927 & 2.426 & 113.64 & 2.923 & $-x, y,-z+3 / 2$ \\
\hline $\mathrm{N} 2-\mathrm{H} 5 \mathrm{~N} \cdots \mathrm{O} 19$ & 0.927 & 2.602 & 148.88 & 3.429 & $-x,-y,-z+1$ \\
\hline $\mathrm{N} 2-\mathrm{H} 6 \mathrm{~N} \cdots \mathrm{O} 2$ & 0.91 & 2.172 & 137.68 & 2.909 & \\
\hline $\mathrm{N} 2-\mathrm{H} 6 \mathrm{~N} \cdots \mathrm{O} 3$ & 0.91 & 2.34 & 133.35 & 3.037 & $-x+1, y,-z+3 / 2$ \\
\hline $\mathrm{N} 2-\mathrm{H} 7 \mathrm{~N} \cdots \mathrm{OW} 2$ & 0.929 & 2.003 & 174.46 & 2.928 & $x-1 / 2,-y+1 / 2,-z+1$ \\
\hline $\mathrm{N} 2-\mathrm{H} 8 \mathrm{~N} \cdots \mathrm{OW} 1$ & 0.893 & 2.009 & 165.93 & 2.884 & $-x+1, y,-z+3 / 2$ \\
\hline 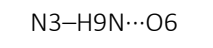 & 0.996 & 1.976 & 149.3 & 2.877 & $-x+1,-y,-z+1$ \\
\hline $\mathrm{N} 3-\mathrm{H} 10 \mathrm{~N} \cdots \mathrm{O} 2$ & 0.877 & 2.105 & 154.81 & 2.922 & \\
\hline $\mathrm{N} 3-\mathrm{H} 11 \mathrm{~N} \cdots \mathrm{O} 18$ & 0.77 & 2.154 & 175.75 & 2.923 & $x-1 / 2,-y+1 / 2,-z+1$ \\
\hline 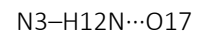 & 0.858 & 2.524 & 116.42 & 3.005 & \\
\hline 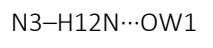 & 0.858 & 2.197 & 149.41 & 2.967 & $-x,-y,-z+1$ \\
\hline $\mathrm{N} 4 \mathrm{~A}-\mathrm{H} 41 \mathrm{~A} \cdots \mathrm{O} 1$ & 1.076 & 1.847 & 171.64 & 2.916 & \\
\hline $\mathrm{N} 4 \mathrm{~A}-\mathrm{H} 42 \mathrm{~A} \cdots \mathrm{O} 2$ & 1.047 & 1.832 & 146.02 & 2.763 & $-x, y,-z+3 / 2$ \\
\hline $\mathrm{N} 4 \mathrm{~A}-\mathrm{H} 44 \mathrm{~A} \cdots \mathrm{Se} 1$ & 0.865 & 3.162 & 173.28 & 4.023 & \\
\hline $\mathrm{N} 4 \mathrm{~A}-\mathrm{H} 44 \mathrm{~A} \cdots \mathrm{O} 14$ & 0.865 & 2.234 & 155.84 & 3.044 & $-x+1 / 2, y-1 / 2, z$ \\
\hline $\mathrm{N} 4 \mathrm{~A}-\mathrm{H} 43 \mathrm{~A} \cdots \mathrm{O} 2$ & 0.85 & 2.268 & 117.26 & 2.763 & \\
\hline $\mathrm{N} 4 \mathrm{~A}-\mathrm{H} 43 \mathrm{~A} \cdots \mathrm{O} 20$ & 0.85 & 2.214 & 154.03 & 3.002 & $-x+1,-y,-z+1$ \\
\hline $\mathrm{N} 4 \mathrm{~B}-\mathrm{H} 41 \mathrm{~B} \cdots \mathrm{O} 12$ & 0.878 & 2.593 & 117.72 & 3.101 & \\
\hline N4B-H41B $\cdots$ OW3 & 0.878 & 2.656 & 147.25 & 3.428 & \\
\hline $\mathrm{N} 4 \mathrm{~B}-\mathrm{H} 42 \mathrm{~B} \cdots \mathrm{O} 8$ & 0.877 & 2.049 & 169.76 & 2.916 & \\
\hline $\mathrm{N} 4 \mathrm{~B}-\mathrm{H} 42 \mathrm{~B} \cdots \mathrm{O} 12$ & 0.877 & 2.561 & 120.65 & 3.101 & \\
\hline $\mathrm{N} 4 \mathrm{~B}-\mathrm{H} 43 \mathrm{~B} \cdots \mathrm{O} 12$ & 0.869 & 2.45 & 132.12 & 3.101 & $x+1 / 2,-y+1 / 2,-z+1$ \\
\hline N4B-H43B $\cdots$ OW3 & 0.869 & 2.637 & 151.74 & 3.428 & \\
\hline $\mathrm{N} 4 \mathrm{~B}-\mathrm{H} 44 \mathrm{~B} \cdots \mathrm{O} 21$ & 0.863 & 2.404 & 132.4 & 3.053 & $-x+1, y,-z+3 / 2$ \\
\hline $\mathrm{N} 4 \mathrm{~B}-\mathrm{H} 44 \mathrm{~B} \cdots \mathrm{O} 21$ & 0.863 & 2.404 & 132.4 & 3.053 & $-x+1,-y,-z+1$ \\
\hline 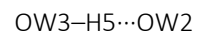 & 0.84 & 2.035 & 177.23 & 2.874 & \\
\hline 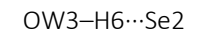 & 0.865 & 2.776 & 140.39 & 3.486 & $-x, y,-z+3 / 2$ \\
\hline 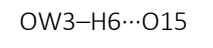 & 0.865 & 2.281 & 177.84 & 3.145 & \\
\hline $\mathrm{N} 1-\mathrm{H} 1 \mathrm{~N} \cdots \mathrm{O} 4$ & 0.893 & 2.182 & 135.69 & 2.889 & $x-1 / 2,-y+1 / 2,-z+1$ \\
\hline $\mathrm{N} 1-\mathrm{H} 1 \mathrm{~N} \cdots \mathrm{O}$ & 0.893 & 2.316 & 129.44 & 2.965 & $-x+1,-y,-z+1$ \\
\hline $\mathrm{N} 1-\mathrm{H} 2 \mathrm{~N} \cdots \mathrm{OW} 2$ & 0.951 & 1.897 & 168.97 & 2.836 & $-x+1 / 2, y-1 / 2, z$ \\
\hline $\mathrm{N} 1-\mathrm{H} 3 \mathrm{~N} \cdots \mathrm{O} 8$ & 1 & 1.960 & 173.47 & 2.956 & $-x+1 / 2,-y+1 / 2, z-1 / 2$ \\
\hline $\mathrm{N} 1-\mathrm{H} 3 \mathrm{~N} \cdots \mathrm{O} 12$ & 1 & 2.571 & 115.34 & 3.132 & $x-1 / 2,-y+1 / 2,-z+1$ \\
\hline $\mathrm{N} 1-\mathrm{H} 4 \mathrm{~N} \cdots \mathrm{O} 4$ & 0.906 & 2.219 & 148.9 & 3.032 & $-x,-y,-z+1$ \\
\hline $\mathrm{N} 1-\mathrm{H} 4 \mathrm{~N} \cdots \mathrm{O} 10$ & 0.906 & 2.361 & 136.46 & 3.082 & $x+1 / 2, y+1 / 2,-z+3 / 2$ \\
\hline
\end{tabular}




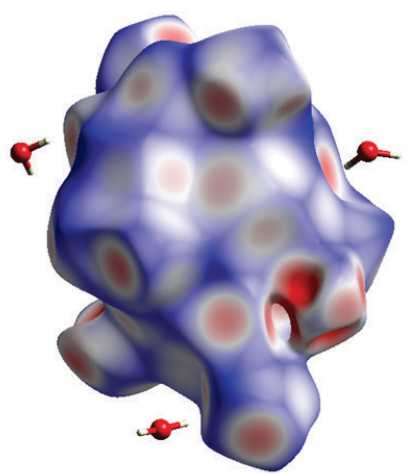

(a) dnorm

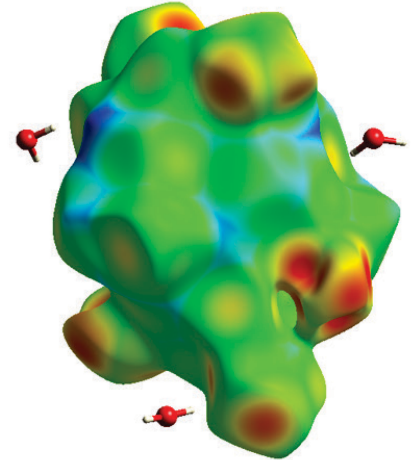

(b) di

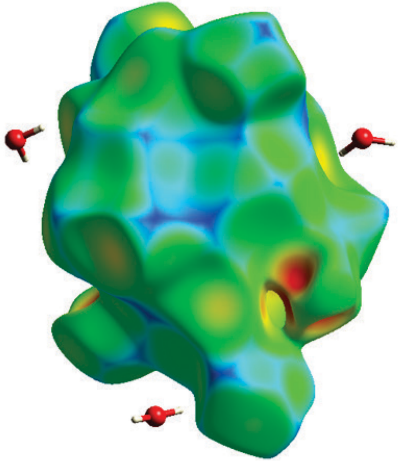

(c) de

Figure 4. Hirshfeld surfaces mapped with d_norm (mapped over a fixed color scale of -1.286 (red) to 1.221 (blue)), d_i and d_e of $\left(\mathrm{NH}_{4}\right)_{4}\left[\mathrm{Se}_{2} \mathrm{Mo}_{5} \mathrm{O}_{21}\right] \cdot 3 \mathrm{H}_{2} \mathrm{O}$.

1.286 (red) and1.221 (blue). Preponderant interactions are mainly $\mathrm{O} \cdots \mathrm{H} / \mathrm{H} \cdots \mathrm{O}$ and the associated surface can be seen in the middle of the Hirshfeld surface as deep red areas whereas the light red areas correspond to the remaining interactions.
The 2D fingerprint plots in Figure 5 provide about these intermolecular interactions. From the plots, it is revealed that the $\mathrm{O} \cdots \mathrm{H} / \mathrm{H} \cdots \mathrm{O}(63.6 \%)$ bonding are a major contributor in the crystal packing. Also, $\mathrm{H} \cdots \mathrm{H}(15.8 \%), \mathrm{O} \cdots \mathrm{O}$

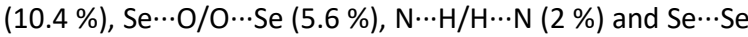
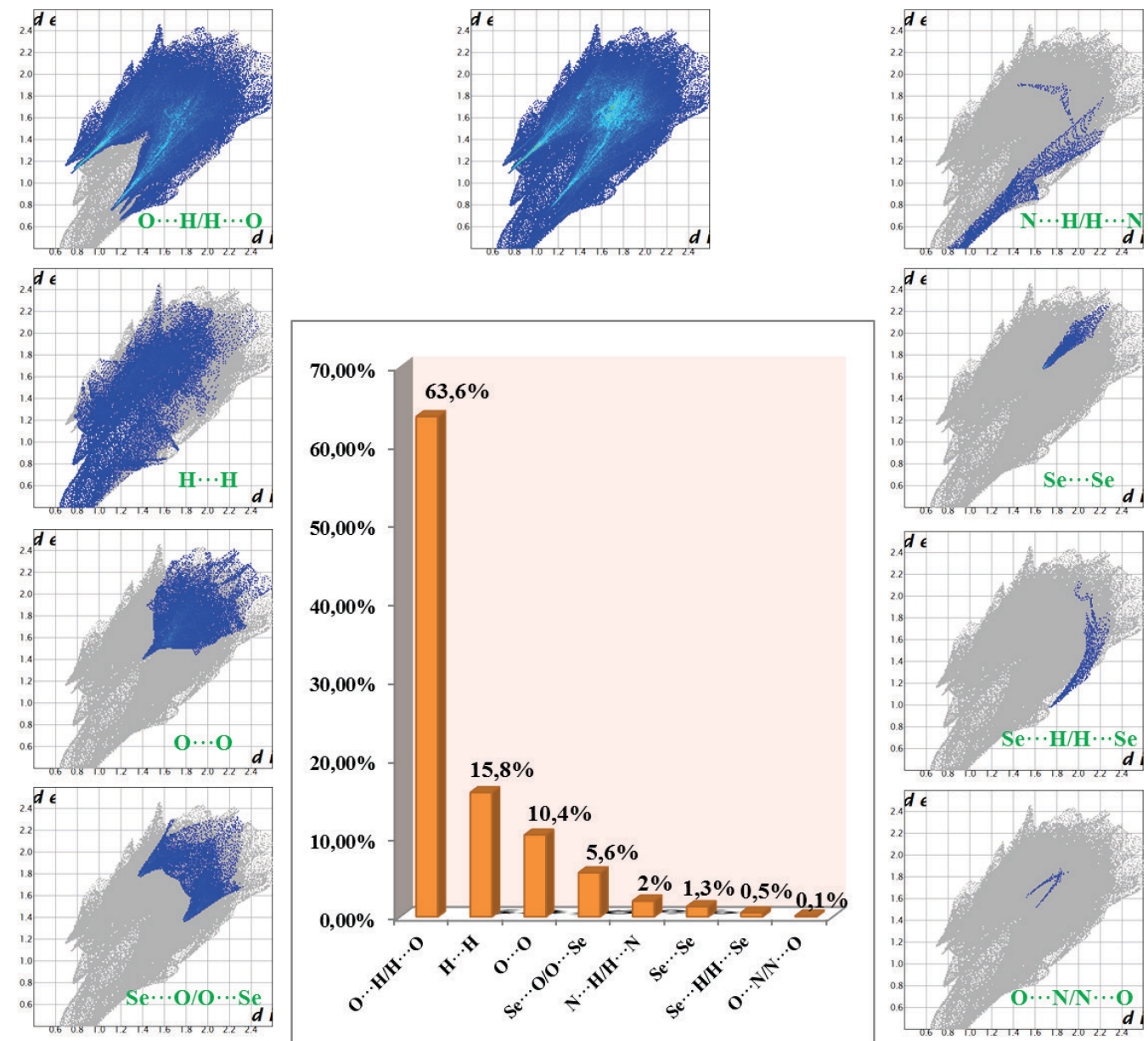

Figure 5. 2D fingerprint plots of ASH. 


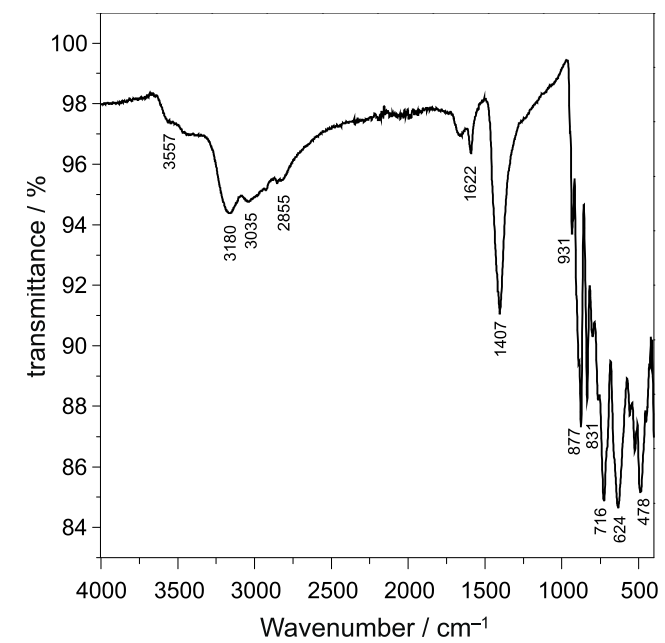

Figure 6. Spectrum of IR of the compound ASH.

$(1.3 \%)$ contacts have their significant contribution to the total area of the surface. All interactions discussed above give rise to the formation of a $3 D$ network of the ASH compound. These findings are in good agreement with those discussed previously.

\section{Vibrational Spectra}

In order to give more information on the crystal structure, we have studied the vibrational properties using infrared absorption. Figure 6 . shows IR spectra of the $\left(\mathrm{NH}_{4}\right)_{4}\left[\mathrm{Se}_{2} \mathrm{Mo}_{5} \mathrm{O}_{21}\right] \cdot 3 \mathrm{H}_{2} \mathrm{O}$ compound at room temperature. The infrared spectra have been measured from 400 to $4000 \mathrm{~cm}^{-1}$. The bonds at 931,877 and $831 \mathrm{~cm}^{-1}$ could are ascribed to the character peaks of $u\left(\mathrm{Mo}-\mathrm{O}_{\mathrm{t}}\right), u\left(\mathrm{Mo}-\mathrm{O}_{\mathrm{b}}-\mathrm{Mo}\right)$ and $u\left(\mathrm{Mo}-\mathrm{O}_{\mathrm{c}}-\mathrm{Mo}\right)$. The bands around 716 and $478 \mathrm{~cm}^{-1}$ can be assigned to the vibrations of the selenite groups. The compound possesses the strong peak $1455 \mathrm{~cm}^{-1}$ which is attributed to the bending vibration of ammonium. The band at $1625 \mathrm{~cm}^{-1}$ corresponds to the vibration of the water molecules. The symmetric and asymmetric $\mathrm{O}-\mathrm{H}$ and $\mathrm{N}-\mathrm{H}$ stretching appear respectively between $3180-3557 \mathrm{~cm}^{-1}$ and $2855-3035 \mathrm{~cm}^{-1}$.

\section{UV-vis Spectra}

When water was used as solvent, the UV spectrum of the compound $\left(\mathrm{NH}_{4}\right)_{4}\left[\mathrm{Se}_{2} \mathrm{Mo}_{5} \mathrm{O}_{21}\right] \cdot 3 \mathrm{H}_{2} \mathrm{O}$ in the range of 180 $800 \mathrm{~nm}$ (Figure 7.) exhibits one peak at $209 \mathrm{~nm}$ ascribed to the ligand-to-metal charge transfers (LMCT) of $\mathrm{O}_{\mathrm{t}}-\mathrm{Mo}$, where electrons are excited from the low-energy electronic states, mainly comprised of oxygen $2 p$ orbital's, to the high energy states, which are mainly comprised of metal $d$ orbital's, whereas the shoulder at $232 \mathrm{~nm}$ is attributed to the (LMCT) between two- and three-coordinated oxygen atoms and the Se atoms in the polyanion. ${ }^{[29-31]}$ The limit value of absorption is $254 \mathrm{~nm}$, indicating an optical energy gap $\left(E_{\mathrm{g}}\right)$ of $4.75 \mathrm{eV}$.

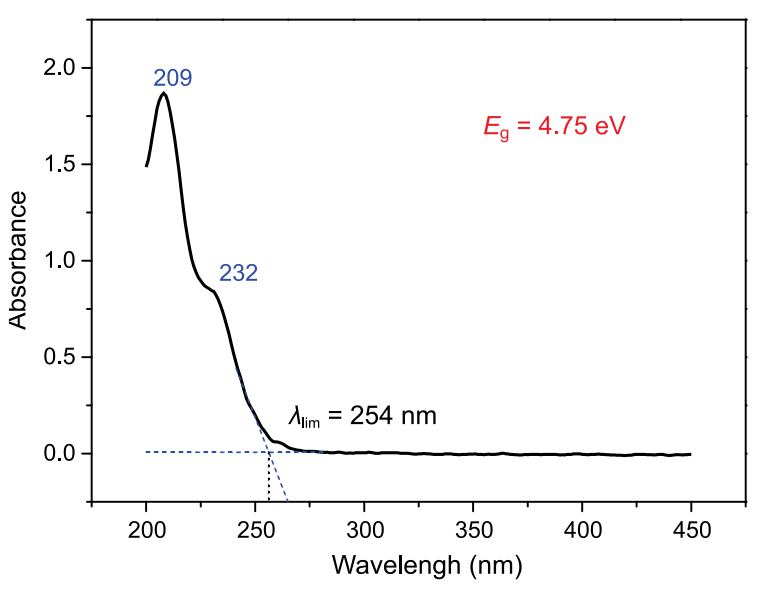

Figure 7. Spectrum of UV of the compound ASH.

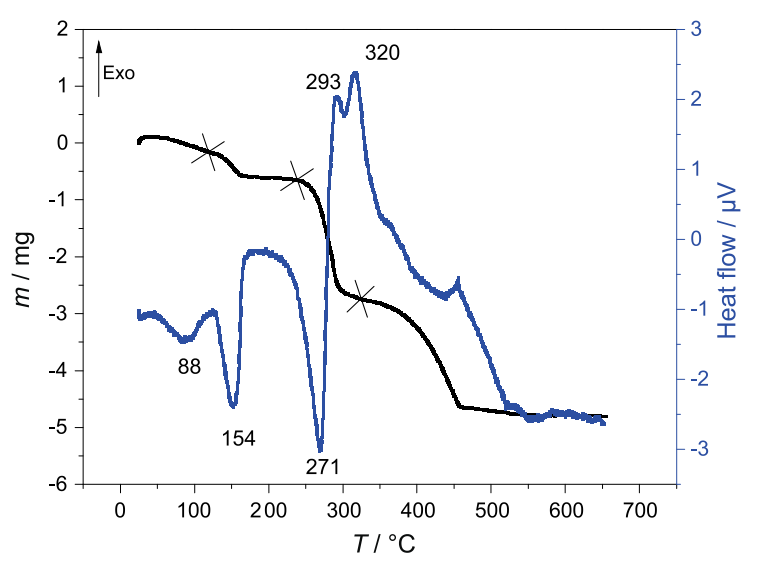

Figure 8. Thermal Behavior of the compound ASH.

\section{Thermal Behavior}

The simultaneous TG-DTA analysis curves of the investigated compound were carried out in air at a heating rate of $10^{\circ} \mathrm{C} / \mathrm{min}$ on a sample of $20 \mathrm{mg}$ placed in a platinum crucible and heated from ambient to $325^{\circ} \mathrm{C}$ (Figure 8).Thermal analysis of the investigated compound in figure 8 reveals the presence of three stages: the first weight loss from 25 to $240{ }^{\circ} \mathrm{C}$ is consistent with the removal of water molecules and pursued with two endothermic peaks. These peaks are accompanied with three shoulders on the DTA curve at 88,154 and $277^{\circ} \mathrm{C}$. These curves corresponds to a loss of three water molecules (experimental weight loss: $3.72 \%$ and theoretical weight loss: $3.42 \%$ ) to obtain an anhydrous framework of $\left(\mathrm{NH}_{4}\right)_{4}\left[\mathrm{Se}_{2} \mathrm{Mo}_{5} \mathrm{O}_{21}\right]$. The second stage, that starts at about $260{ }^{\circ} \mathrm{C}$ and ends above $300{ }^{\circ} \mathrm{C}$, is assigned to the degradation of ammonium groups (experimental loss: $65.46 \%$ and theoretical loss: $60.85 \%$ ). From $300{ }^{\circ} \mathrm{C}$ to $460{ }^{\circ} \mathrm{C}$ the degradation of $\mathrm{Se}_{2} \mathrm{O}_{3}{ }^{2-}$ groups initiated. Above $460{ }^{\circ} \mathrm{C}$, the degradation of the compound continues until its total degradation at $660^{\circ} \mathrm{C}$. 


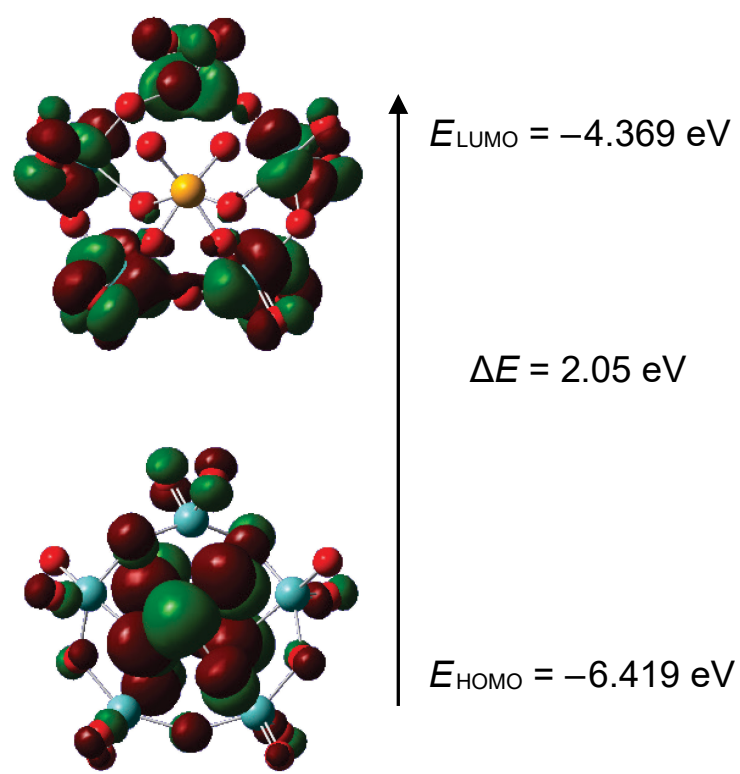

Figure 9. Frontier molecular orbital's (HOMO and LUMO) of compound ASH.

\section{Frontier Molecular Orbital Analysis}

The frontier molecular orbitals called highest occupied molecular (HOMO) and lowest unoccupied molecular orbital (LUMO) are very important parameters for theoretical chemistry. The difference between (HOMO) and (LUMO) termed energy gap was used to determine the ability of a molecule to absorb light, and it is useful to prove the bioactivity from intermolecular charge transfer. Also, it plays an important role in the electronic properties, corrosion inhibition of metal surfaces and interactions. The map of frontier molecular orbitals of the title compound is

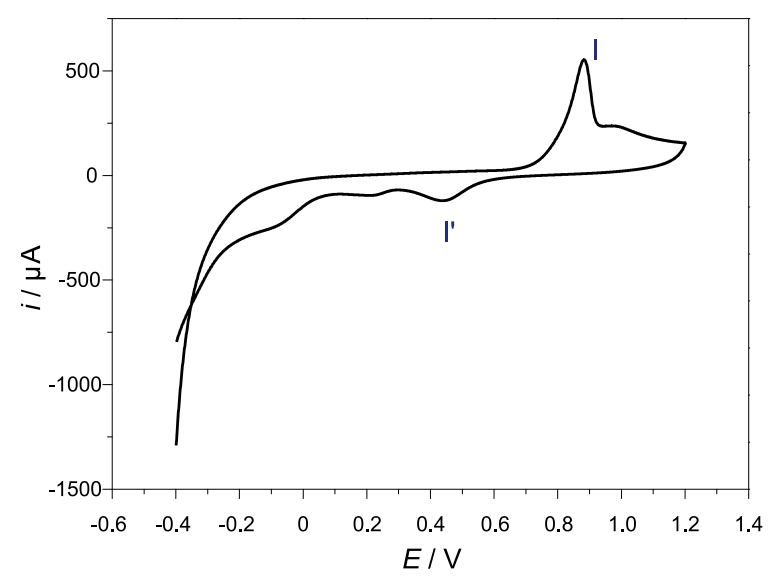

(a) illustrated in Figure 9. The LUMO energy is $-4.369 \mathrm{eV}$ and the HOMO energy is $-6.419 \mathrm{eV}$. The HOMO-LUMO gap for compound ASH is $2.05 \mathrm{eV}$.

\section{Cyclic Voltammetry}

In order to study the redox properties of the compound, the electrochemical behavior, in $0.5 \mathrm{M}$ of $\mathrm{H}_{2} \mathrm{SO}_{4}$ aqueous solution $\left(10^{-3} \mathrm{~mol} \mathrm{~L}^{-1}\right)$, was performed Figure 10.a reports the cyclic voltammogram of ASH compound at scan rate of $20 \mathrm{mVs}^{-1}$. As it can be noticed that the potential range -0.4 to $1.4 \mathrm{mV}$, one quasi-reversible redox peak appeared. The half-wave potential $E_{1 / 2}=\left(E_{\mathrm{pa}}+E_{\mathrm{pc}}\right) / 2$ is $0.671 \mathrm{~V}$, which is attributed to one electron process of Molybdenum. With an increase of the scan rates from $20 \mathrm{mV} / \mathrm{s}$ to $100 \mathrm{mV} / \mathrm{s}$, the peak potentials change gradually. The cathodic peak potentials shift towards the negative direction whereas the corresponding anodic peak potentials to the positive direction as shown in Figure 10.b. The peaks, current is proportional to the scan rates, which indicates that the redox process on the electrode surface is controlled.

\section{Thermodynamic Properties}

In this work, the theoretical thermodynamic properties of title compound were calculated to get information about the thermodynamic energies and their variations with temperature. The thermodynamic functions at $298.15 \mathrm{~K}$ and 1.00 atm, namely the zero point energy (ZPE), enthalpy $\left(H_{m}^{\circ}\right)$, heat capacity $\left(C_{p, m}^{\circ}\right)$, and the entropy $\left(S_{m}^{\circ}\right)$, are calculated and are listed in Table 5. Also, the statistical thermochemical analyses were calculated from 100 to $1000 \mathrm{~K}$ on the basis of vibrational analysis and the results are listed in Table 6. The correlation graphs are shown in Figure 11. These results postulate that the temperature has a significant influence on the thermodynamic properties of compound ASH.

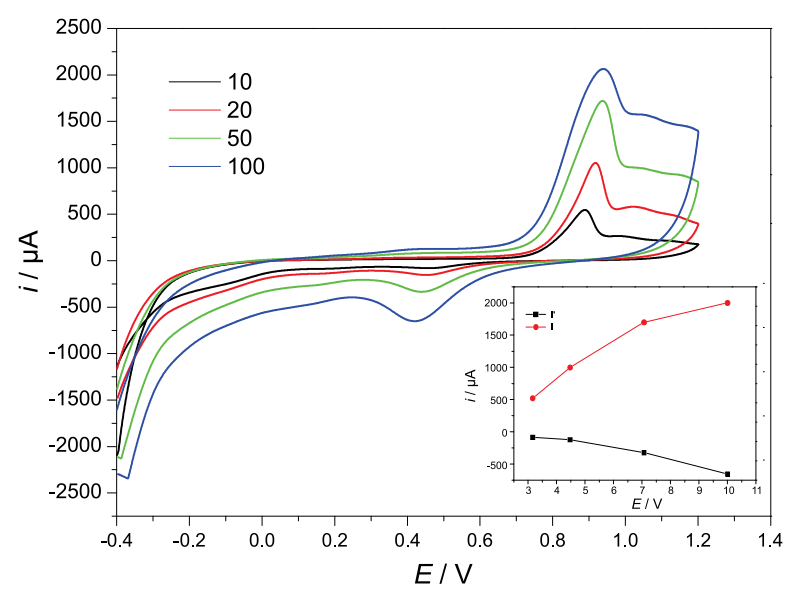

(b)

Figure 10. $\mathrm{CV}$ of compound $\mathrm{ASH}$ in $0.5 \mathrm{~mol} \mathrm{~L}^{-1} \mathrm{H}_{2} \mathrm{SO}_{4}$ solution at a scan rate of $20 \mathrm{mV} \mathrm{s}^{-1}$ (a); $\mathrm{CVs}$ of ASH in $0.5 \mathrm{~mol} \mathrm{~L}^{-1} \mathrm{H}_{2} \mathrm{SO}_{4}$ solution at scan rates of $10,20,50$ and $100 \mathrm{mV} \mathrm{s}^{-1}$ (b). 


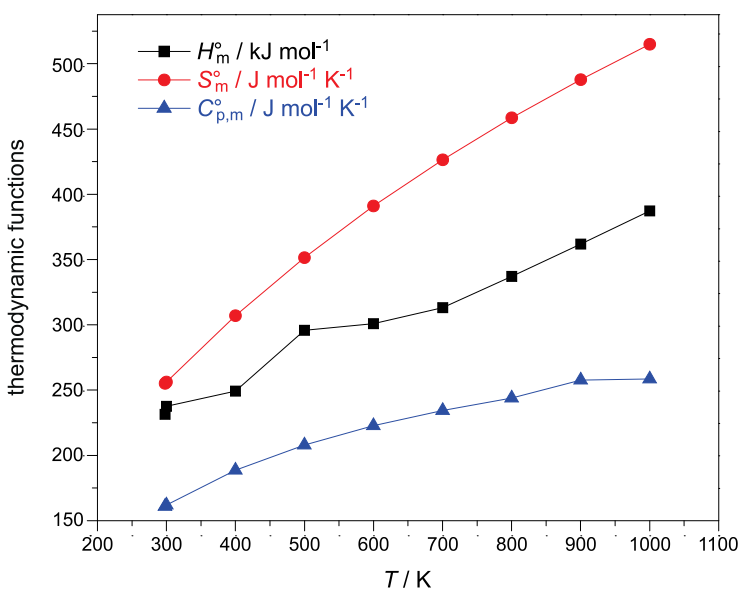

Figure 11. Variation in thermodynamic parameters with temperature for ASH.

\section{CONCLUSION}

In summary conventional solution method synthesis has permitted the self-assembly of one inorganic supramolecular molybdate phase. The main geometrical feature of the compound ASH is the existence of anionic clusters. These $\left[\mathrm{Se}_{2} \mathrm{Mo}_{5} \mathrm{O}_{21}\right]^{4-}$ groups are covalently linked by ammonium cations and solvent molecules to form three dimensional frameworks. It is important to emphasize that few type of anions with selenite groups have been previously described. HS analysis leads to conclude that hydrogen bonds contribute well in the crystal packing

Table 5. Thermodynamic properties at the $\mathrm{PM} 6$ level of $\left(\mathrm{NH}_{4}\right)_{4}\left[\mathrm{Se}_{2} \mathrm{Mo}_{5} \mathrm{O}_{21}\right] \cdot 3 \mathrm{H}_{2} \mathrm{O}$ at $298.15 \mathrm{~K}$ and $1.00 \mathrm{~atm}$

\begin{tabular}{|c|c|}
\hline Parameters & Values \\
\hline Zero point energy, ZPE $\left(\mathrm{kJ} \mathrm{mol}^{-1}\right)$ & 204.208 \\
\hline \multicolumn{2}{|l|}{ Enthalpy $H_{\mathrm{m}}^{\circ}$} \\
\hline Total $\left(\mathrm{kJ} \mathrm{mol}^{-1}\right)$ & 231.898 \\
\hline Translational $\left(\mathrm{kJ} \mathrm{mol}^{-1}\right)$ & 0.889 \\
\hline Rotational (kJ mol-1) & 0.889 \\
\hline Vibrational $\left(\mathrm{kJ} \mathrm{mol}{ }^{-1}\right)$ & 230.114 \\
\hline \multicolumn{2}{|l|}{ Heat capacity $C_{p, \mathrm{~m}}^{\circ}$} \\
\hline Total $\left(\mathrm{J} \mathrm{mol} \mathrm{l}^{-1} \mathrm{~K}^{-1}\right)$ & 161.174 \\
\hline Translational $\left(\mathrm{J} \mathrm{mol}^{-1} \mathrm{~K}^{-1}\right)$ & 2.98 \\
\hline Rotational $\left(\mathrm{J} \mathrm{mol}^{-1} \mathrm{~K}^{-1}\right)$ & 2.98 \\
\hline Vibrational $\left(\mathrm{J} \mathrm{mol}^{-1} \mathrm{~K}^{-1}\right)$ & 155.509 \\
\hline \multicolumn{2}{|l|}{ Entropy $S_{\mathrm{m}}^{\circ}$} \\
\hline Total $\left(\mathrm{J} \mathrm{mol} \mathrm{l}^{-1} \mathrm{~K}^{-1}\right)$ & 255.927 \\
\hline Translational (J mol $\left.{ }^{-1} \mathrm{~K}^{-1}\right)$ & 47.269 \\
\hline Rotational $\left(\mathrm{J} \mathrm{mol}^{-1} \mathrm{~K}^{-1}\right)$ & 40.137 \\
\hline Vibrational $\left(\mathrm{J} \mathrm{mol}^{-1} \mathrm{~K}^{-1}\right)$ & 168.521 \\
\hline
\end{tabular}

Table 6. Thermodynamic properties at different temperatures at PM6 level of ASH

\begin{tabular}{cccc}
\hline$T / \mathrm{K}$ & $H_{\mathrm{m}}^{\circ} / \mathrm{kJ} \mathrm{mol}^{-1}$ & $S_{\mathrm{m}}^{\circ} / \mathrm{J} \mathrm{mol}^{-1} \mathrm{~K}^{-1}$ & $C_{p, \mathrm{~m}}^{\circ} / \mathrm{J} \mathrm{mol}^{-1} \mathrm{~K}^{-1}$ \\
\hline 100 & 207.884 & 129.973 & 71.545 \\
200 & 217.768 & 198.170 & 124.272 \\
298.15 & 231.898 & 255.927 & 161.174 \\
300 & 238.191 & 256.940 & 162.058 \\
400 & 249.815 & 308.027 & 188.921 \\
500 & 296.733 & 352.834 & 208.467 \\
600 & 301.891 & 392.572 & 223.290 \\
700 & 314.287 & 428.211 & 234.998 \\
800 & 338.280 & 460.449 & 244.540 \\
900 & 363.145 & 490.011 & 258.521 \\
1000 & 388.743 & 517.185 & 259.271 \\
\hline
\end{tabular}

formation and interaction within the crystal packing. Moreover, spectral characterizations are carried out using FT-IR. The assignments of the vibrational modes have been performed based on the main characteristic vibrations of the Strandberg anion ring and ammoniums groups. The calculated HOMO/LUMO gap energy is $2.05 \mathrm{eV}$, point to the stability of structure. The structure was optimized geometrically. In general, the observed and calculated parameters are in good agreement. A good correlation was found between the experimental and the calculated parameters and some theoretical properties of the title compound were studied.

Acknowledgment. The authors gratefully acknowledge the support of the Tunisian Ministry of Higher Education and Scientific Research and the technical help for X-ray crystallographic mesurement by Michel GIORGI, Research Engineer in Federation of Chemical Sciences of Marseille.

Supplementary Information. The Crystallographic data of compound ASH have been deposited with the Fachinformationszentrum Karlsruhe as supplementary publication for compound ASH (CSD-number 433462). This data can be obtained at https://icsd.fiz-karlsruhe.de/.

\section{REFERENCES}

[1] J. J. De Luyart Lubice, F. C. De Luyar Lubice, Extractos de las Juntas Generales celebradas por la Real Sociedad Bascongada 1783, p.46.

[2] P. Gouzerh, M. Che, Actual. Chim. 2006, 298, 9-22

[3] M. Ibrahim, Y. Xiang, B. S. Bassil, et al., J. Inorg. Chem. 2013, 52 (15), 8399-8408.

[4] S. Pintado, S. Goberna-Ferrón, E. C. Escudero-Adán, J. R. Galán-Mascarós, J. Am. Chem. Soc. 2013, 135 (36), 13270-13273. https://doi.org/10.1021/ja406242y 
[5] A. Ambrosi, C. K. Chua, A. Bonanni, M. Pumera, J. Chem. Rev. 2014, 114 (14), 7150-7188. https://doi.org/10.1021/cr500023c

[6] S. X. Guo, Y. Liu, C.-Y. Lee, A. M. Bond, J. Zhang, Y. V. Geletii, J. Ener Env. Sci. 2013, 6 (9), 2654-2663. https://doi.org/10.1039/c3ee41892h

[7] J. Berzelius, J. Ann. Phys. 1826, 82 (4), 369-392. https://doi.org/10.1002/andp.18260820402

[8] Y.-M. Sang, L.-K. Yan, N.-N. Ma, J.-P. Wang, Z.-M. Su, J. Phys. Chem. A. 2013, 117, 2492-2498. https://doi.org/10.1021/jp400506z

[9] G. M. Sheldrick. Acta. Crystallogr. A.2008, 64, 112122. https://doi.org/10.1107/S0108767307043930

[10] M. N. Burnett, C. K. Johnson. ORTEP III. Report ORNL6895; Oak Ridge National Laboratory (Oak Ridge, TN, USA, 1996).

[11] K. Brandenburg. DIAMOND Visual Crystal Structure Information System, 1997.

[12] D. Jayatilaka, D. J. Grimwood, A. Lee, et al., TONTO-A System for Computational Chemistry, The University of Western Australia, Nedlands, Australia, 2005.

[13] R. Neumann, Prog. Inorg. Chem. 1998, 47, 317-370.

[14] Spartan 14, Wave function Inc. Irvine, CA, USA, 2014.

[15] T. Hori, S. Himeno, O. J. Tamada. J. Chem. Soc. Dalton Trans. 1992, 275-280.

[16] P. Hohenberg, W. Kohn, J. Phys. Rev. B 1964, 136, 864-871. https://doi.org/10.1103/PhysRev.136.B864

[17] W. Kohn, J. Phys. Rev. 1964, 133, 171-181. https://doi.org/10.1103/PhysRev.133.A171

[18] A. Becke, J. Chem. Phys. 1993, 98, 5648-5652. https://doi.org/10.1063/1.464913

[19] C. Lee, W. Yang, R. Parr, J. Phys. Rev. B 1988, 37, 785789. https://doi.org/10.1103/PhysRevB.37.785

[20] E. Burholder, V. Golub, C. J. O'Connor, J. Zubieta, J. Chem. Commun. 2003, 17, 2128-2129.
[21] R. B. Fu, X. T. Wu, S. M. Hu, J. J. Zhang, Z. Y. Fu, W. X. Du, S. Q. Xia, Eur. J. Inorg. Chem. 2003, 9, 17981801.

https://doi.org/10.1002/ejic.200200678

[22] E. Burholder, V. Golub, C. J. O'Connor, J. Zubieta, J. Inorg. Chem. 2003, 42, 6729-5740. https://doi.org/10.1021/ic030169o

[23] A. Abhishek, Kantak, S. Potavathri, R. A. Barham, K. M. Romano, B. DeBoef. J. Am. Chem. Soc. 2011, 133, 49, 19960-19965. https://doi.org/10.1021/ja2087085

[24] Y. Porter, P. Shiv Halasyamani. J. Sol State Chem. 2003, 174, 441-449. https://doi.org/10.1016/S0022-4596(03)00296-2

[25] R. K. Mudsainiyan, S. K. Pandey, Z. anorg. allg. Chem. 2017, 643(20), 1245-1252. https://doi.org/10.1002/zaac.201700182

[26] B. V. Pandiyan, P. Deepa, P. Kolandaivel. J. Mol. Model. 2017, 23:16.

https://doi.org/10.1007/s00894-016-3181-z

[27] J. Hilbert, C. Näther, W. Bensch, Z. anorg. allg. Chem. 2017, 643(23), 1861-1866. https://doi.org/10.1002/zaac.201700193

[28] S. K. Wolff, D. J. Grimwood, J. J. McKinnon, M. J. Turner, D. Jayatilaka, M. A. Spackman, Crystal Explorer (Version 3.1), University of Western Australia, Perth, 2012.

[29] X. Hu, N. Chen, W. Li, J. Mol. Model. 2016, 22:170. https://doi.org/10.1007/s00894-016-3031-z

[30] W. H. Baur, Acta Crystallogr. B 1974, 30, 11951215. https://doi.org/10.1107/S0567740874004560

[31] X. M. Zhang, B. Z. Shen, X. Z. You, H. K. Fun, Polyhedron 1997, 16, 95-102. https://doi.org/10.1016/0277-5387(96)00236-7 